Check for updates

Cite this: RSC Adv., 2017, 7, 22360

Received 9th March 2017 Accepted 17th April 2017

DOI: $10.1039 / \mathrm{c} 7 \mathrm{ra02889j}$

rsc.li/rsc-advances

\section{Application of quinazoline and pyrido[3,2-d] pyrimidine templates to design multi-targeting agents in Alzheimer's disease $\uparrow$}

\begin{abstract}
Tarek Mohamed, ${ }^{\text {ab }}$ Mandeep K. Mann ${ }^{a}$ and Praveen P. N. Rao (iD *a
A quinazoline and pyrido[3,2-d]pyrimidine based compound library was designed, synthesized and evaluated as multi-targeting agents aimed at Alzheimer's disease (AD). The SAR studies identified compound $8 \mathrm{~h}$ (8-chloro- $N^{2}$-isopropyl- $N^{4}$-phenethylquinazoline-2,4-diamine) as a potent inhibitor of $\mathrm{A} \beta 40$ aggregation $\left(\mathrm{IC}_{50}=900 \mathrm{nM}\right)$ which was 3.6-fold more potent compared to the reference agent curcumin $\left(\mathrm{A} \beta 40 \mathrm{IC} \mathrm{C}_{50}=3.3 \mu \mathrm{M}\right)$. It also exhibited dual ChE inhibition ( $\mathrm{AChE} I \mathrm{C}_{50}=8.6 \mu \mathrm{M}$; $\mathrm{BuChE} \mathrm{IC} \mathrm{C}_{50}=$ $2.6 \mu \mathrm{M})$. Compound 9h (8-chloro- $N^{4}$-(3,4-dimethoxyphenethyl)- $N^{2}$-isopropylquinazoline-2,4-diamine) was identified as the most potent $A \beta 42$ aggregation inhibitor $\left(\mathrm{IC}_{50} \sim 1.5 \mu \mathrm{M}\right)$. Transmission electron microscopy (TEM) imaging demonstrates their anti-A $340 / A \beta 42$ aggregation properties. Compound $8 \mathrm{e}$ was identified as a potent BuChE inhibitor (BuChE IC $50=100 \mathrm{nM}$ ) which was 36-fold more potent compared to donepezil (BuChE $I C_{50}=3.6 \mu \mathrm{M}$ ). The pyrido[3,2- $d$ ]pyrimidine bioisostere 10b $\left(N^{2}-\right.$ isopropyl- $N^{4}$-phenethylpyrido[3,2-d]pyrimidine-2,4-diamine) exhibited good anti-A $\beta$ activity (A $\beta 40 I C_{50}$ $=1.1 \mu \mathrm{M})$, dual ChE inhibition and iron-chelating properties $(23.6 \%$ chelation at $50 \mu \mathrm{M})$. These investigations demonstrate the usefulness of either a quinazoline or a pyrido[3,2- $d$ ]pyrimidine based ring scaffold in the design of multi-targeting agents to treat AD.
\end{abstract}

\section{Introduction}

Alzheimer's disease (AD) is a neurodegenerative disorder with no cure in sight. It is anticipated that with an aging population and increasing lifespan, the social and economic burden is going to multiply in the years to come. Current AD research indicates that many factors are involved in its pathophysiology. Due to the ever-growing complexity of $\mathrm{AD}$, it is no surprise that the shift toward multi-targeting small molecule candidates which can counter the various facets of the disease, as the next generation $\mathrm{AD}$ treatments is increasing. ${ }^{1-3}$ While current pharmacotherapy options rely on cholinesterase inhibitors (donepezil, rivastigmine and galantamine) that reduce the degradation of the neurotransmitter acetylcholine (ACh) and an $N$-methyl-D-aspartate antagonist (memantine), these were not designed as multi-targeting agents and provide only symptomatic relief., ${ }^{4,5}$ The role of beta-amyloid (A $\beta$ ) which tends to form neurotoxic aggregates, cholinesterases (ChE) that degrade ACh which facilitates neurotransmission and oxidative stress

${ }^{a}$ School of Pharmacy, Health Sciences Campus, University of Waterloo, Waterloo, Ontario, Canada N2L 3G1. E-mail: praopera@uwaterloo.ca; Tel: +1-519-888-4567 ext. 21317

${ }^{b}$ Department of Chemistry and School of Pharmacy, University of Waterloo, Waterloo, Ontario, Canada N2L $3 G 1$

$\dagger$ Electronic supplementary information (ESI) available: Includes ${ }^{1} \mathrm{H}$ NMR spectra. See DOI: $10.1039 / \mathrm{c} 7 \mathrm{ra02889j}$ including metal-induced neurotoxicity in $\mathrm{AD}$ disease pathophysiology, highlights the need to design and develop novel therapies to target multiple pathways. ${ }^{6-10}$

As part of our research program aimed at designing multitargeting small molecules, we have investigated the development of novel agents including quinazolines that exhibit $A \beta$ aggregation inhibition, dual acetylcholinesterase (AChE) and butyrylcholinesterase (BuChE) inhibition and possess radical scavenging activity. ${ }^{\mathbf{1 1 , 1 2}}$ In this regard, dual inhibition of both AChE and BuChE is known to be beneficial as BuChE can process $\mathrm{ACh}$ in advance stages of $\mathrm{AD} .{ }^{13}$ Building on our recent efforts on multi-targeting small molecules, herein we present the structure-activity relationship (SAR) studies of substituted quinazolines and its bioisostere, pyrido $[3,2-d]$ pyrimidine ring template (Fig. 1). Several compounds from this series exhibited
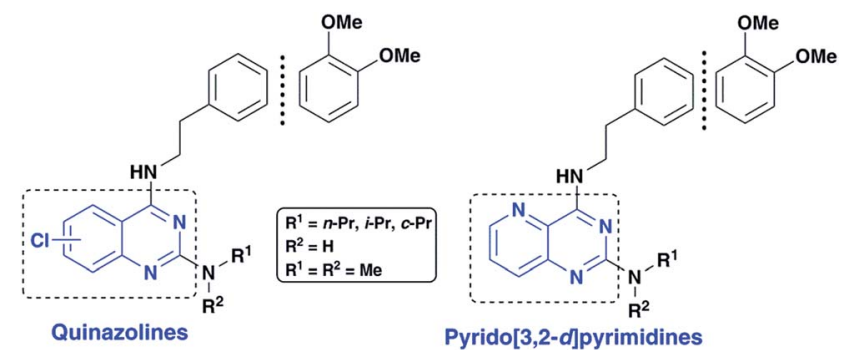

Fig. 1 SAR studies of quinazoline and pyrido[3,2- $d$ ]pyrimidines as multi-targeting anti-AD agents. 
<smiles>Nc1cc[14c](Cl)[c][X]1C(=O)O</smiles>

1a-d, $\mathrm{X}=\mathrm{CH}$ or $\mathrm{N}$

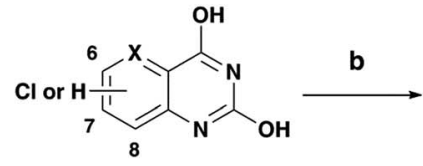

2a-d, $\mathrm{X}=\mathrm{CH}$ or $\mathrm{N}$

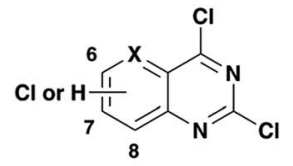

3a-d, $\mathrm{X}=\mathrm{CH}$ or $\mathrm{N}$

Scheme 1 Reagents and conditions: (a) urea, pressure vial, $150-155^{\circ} \mathrm{C}, 2 \mathrm{~h}$; (b) toluene, $\mathrm{N}, \mathrm{N}$-diethylaniline, $\mathrm{POCl} 3,0-105^{\circ} \mathrm{C}$, reflux, $14-16 \mathrm{~h}$.

desirable multi-targeting ability including dual $\mathrm{A} \beta / \mathrm{ChE}$ inhibition and iron chelation properties. The road toward this library of 32 derivatives (8-15) started by first reacting the substitutedchloro-2-aminobenzoic or picolinic acids (1a-d, Scheme 1) with urea to afford the quinazoline or pyrido[3,2- $d]$ pyrimidine ring template (2a-d), followed by 2,4-dichlorination with $\mathrm{POCl}_{3}$ to obtain 2,4,6-, 2,4,7- or 2,4,8-trichloroquinazolines (3a-c) or 2,4dichloropyrido[3,2- $d]$ pyrimidine (3d) respectively $\quad(65-80 \%$ yield, Scheme 1). ${ }^{12}$

The $N^{4}$-substituted dichloroquinazolines $(4 \mathbf{a}-\mathbf{c}$ and $\mathbf{5 a}-\mathbf{c})$ or $N^{4}$-substituted-2-chloropyrido[3,2- $\left.d\right]$ pyrimidine (6a and 7a) intermediates were obtained in moderate to good yields $(\sim 75-$ $90 \%$ ) by coupling 3a-d with phenethylamine or 3,4-dimethoxyphenethylamine in the presence of $N, N$-diisopropylethylamine (DIPEA) under reflux for 4 hours (Scheme 2). Displacement of the $\mathrm{C} 2$ chlorine in $\mathbf{4 a - c}, \mathbf{5 a - c}, \mathbf{6 a}$ and $7 \mathbf{a}$ was readily achieved by heating with respective amines ( $n$-propylamine, isopropylamine, cyclopropylamine or $N, N$-dimethylamine) with 1,4 dioxane in the presence of DIPEA, in a pressure vial for $2 \mathrm{~h}$ to afford the quinazoline (Qnz) and pyrido[3,2- $d]$ pyrimidine (Ppd) based compound library 8a-i, 9a-i, 10a-c, 11a-c, 12a-c, 13a-c, 14a and 15a with yields ranging from $68-78 \%$ (Scheme 1). The synthesized quinazoline derivatives were evaluated for their ability to modulate the aggregation kinetics of $A \beta 40$ and $A \beta 42$ using the thioflavin $\mathrm{T}$ (ThT) fluorescence assay. ${ }^{12,14}$ Their cholinesterase ( $h \mathrm{AChE} / h \mathrm{BuChE})$ inhibition activity was determined using the Ellman's protocol. ${ }^{12,15}$ We identified few chloroquinazoline and pyrido[3,2- $d]$ pyrimidines that exhibited excellent $\mathrm{A} \beta$ aggregation inhibition, dual $\mathrm{ChE}$ inhibition and iron-chelation properties thereby demonstrating multitargeting ability.

\section{Results and discussion}

\subsection{Inhibition of $A \beta$ aggregation}

The results of the SAR investigation on the anti-A $\beta$ aggregation properties of chloroquinazolines and pyrido[3,2- $d]$ pyrimidines is shown in Table 1. Examining the SAR of $\mathrm{C} 4$ phenethylaminebased chloroquinazolines (8a-i), shows that chlorine placement on the quinazoline ring had an effect on anti- $\mathrm{A} \beta$ activity with the 8-Cl placement exhibiting superior $A \beta$ aggregation inhibition. The activity order was $8-\mathrm{Cl}>7-\mathrm{Cl}>6$-Cl with respect to both $A \beta 40 / A \beta 42$ inhibition. While 8a-c was ineffective toward $A \beta 42$, others in the group showed inhibition ranging from $\sim 3.9-12$ $\mu \mathrm{M}$, with $\mathbf{8 h}$ being the most potent $\mathrm{A} \beta 42$ inhibitor. Significant A $\beta 40$ aggregation inhibition was observed with compounds $8 \mathbf{8}-\mathbf{i}$ $(\sim 900 \mathrm{nM}$ to $3.7 \mu \mathrm{M})$, with $8 \mathrm{~h}(8-\mathrm{Cl}, \mathrm{C} 2 \mathrm{i}-\mathrm{Pr})$ being the most potent inhibitor $\left(\mathrm{A} \beta 40 \mathrm{IC}_{50}=900 \mathrm{nM}\right)$ and was 3.6-fold more potent compared to the reference agent curcumin $\left(\mathrm{A} \beta 40 \mathrm{IC}_{50}=\right.$ 3.3 $\mu \mathrm{M}$, Table 1). The addition of a $\mathrm{C} 4$ 3,4-dimethoxylphenethylamine substituent in compounds (9a-i) generally provided dual inhibition of both $\mathrm{A} \beta 40$ and $\mathrm{A} \beta 42$ aggregation except for the 7-chloro derivative $9 e$ (Table 1 ). Compound $9 \mathbf{h}$ (8chloro, $\mathrm{C} 2 \mathrm{i}-\mathrm{Pr}$ ) was identified as a good inhibitor of both $\mathrm{A} \beta 40$ and $\mathrm{A} \beta 42\left(\mathrm{~A} \beta 40 \mathrm{IC}_{50} \sim 4.0 \mu \mathrm{M} ; \mathrm{A} \beta 42 \mathrm{IC}_{50} \sim 1.5 \mu \mathrm{M}\right)$. Significantly, it was $\sim 6.6$-fold and 10-fold more potent toward $\mathrm{A} \beta 42$ compared to reference agents resveratrol $\left(\mathrm{A} \beta 42 \mathrm{IC}_{50}=15.3\right)$ and curcumin $\left(\mathrm{A} \beta 42 \mathrm{IC}_{50}=9.9 \mu \mathrm{M}\right)$. Replacing the quinazoline ring template with a pyrido $[3,2-d]$ pyrimidine bioisostere was generally ineffective. In this group of compounds, the $\mathrm{C} 4$ phenethylamine derivatives 10a-c were better than the corresponding C4 3,4-dimethoxyphenethylamine derivatives 11a-c with compound 10b identified as the most potent $\mathrm{A} \beta 40$ aggregation

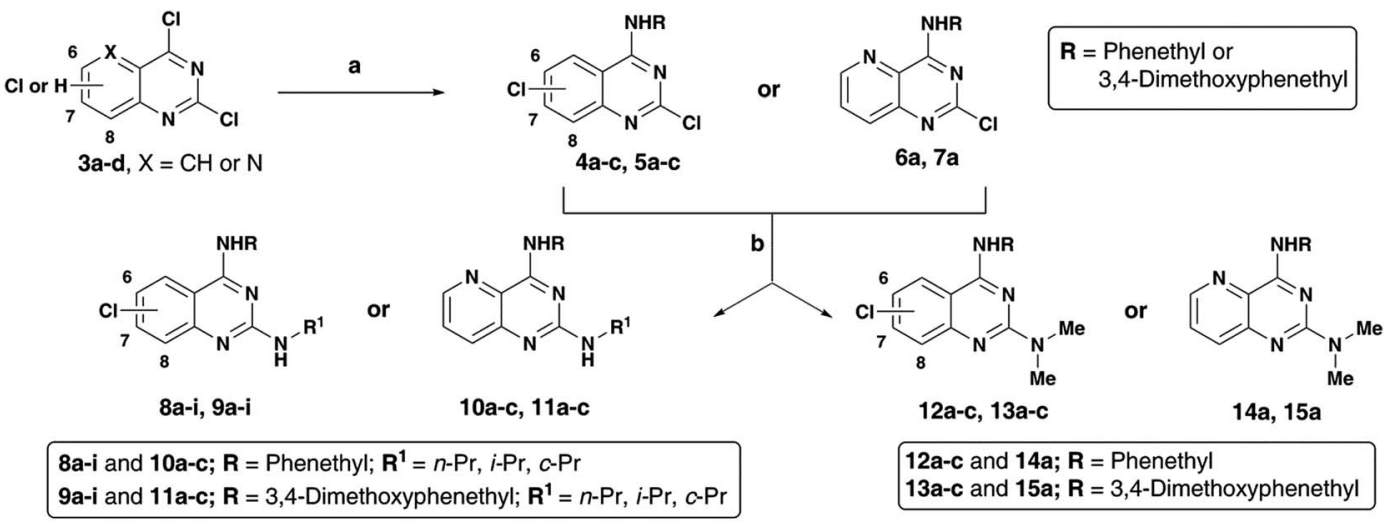

Scheme 2 Reagents and conditions: (a) phenethylamine or 3,4-dimethoxyphenethylamine, DIPEA, ethanol, reflux, $80-85^{\circ} \mathrm{C}, 4 \mathrm{~h}$; (b) alkylamine, DIPEA, 1,4-dioxane, $150-155^{\circ} \mathrm{C}$, pressure vial, $2 \mathrm{~h}$. 
Table 1 Amyloid- $\beta$ (A $\beta 40 / A \beta 42)$ inhibition activity of quinazolines (8, $9,12$ and 13$)$ and pyrido[3,2-d]pyrimidines (10,11, 14 and 15)

\begin{tabular}{|c|c|c|c|c|}
\hline \multirow[b]{2}{*}{ Compd } & \multirow[b]{2}{*}{$\mathrm{R}^{1}$} & \multirow{2}{*}{$\begin{array}{l}\text { Chloride } \\
\text { substitution }\end{array}$} & \multicolumn{2}{|c|}{$\mathrm{IC}_{50}^{a, b}(\mu \mathrm{M})$} \\
\hline & & & $\mathrm{A} \beta 40$ & $\mathrm{~A} \beta 42$ \\
\hline $8 \mathbf{a}$ & $n$-Pr & C6 & $>25$ & $>25$ \\
\hline $8 b$ & $\mathrm{i}-\mathrm{Pr}$ & C6 & $8.6 \pm 0.7$ & $>25$ \\
\hline $8 c$ & $c-\mathrm{Pr}$ & C6 & $8.7 \pm 0.9$ & $>25$ \\
\hline $8 d$ & $n$-Pr & $\mathrm{C} 7$ & $6.9 \pm 1.4$ & $4.6 \pm 0.9$ \\
\hline $8 \mathrm{e}$ & $\mathrm{i}-\mathrm{Pr}$ & $\mathrm{C} 7$ & $6.1 \pm 1.3$ & $7.2 \pm 1.6$ \\
\hline $8 f$ & $c-\mathrm{Pr}$ & $\mathrm{C} 7$ & $4.8 \pm 1.0$ & $11.7 \pm 2.0$ \\
\hline $8 g$ & $n$-Pr & $\mathrm{C} 8$ & $3.7 \pm 0.5$ & $6.5 \pm 0.4$ \\
\hline $8 \mathrm{~h}$ & $\mathrm{i}-\mathrm{Pr}$ & $\mathrm{C} 8$ & $0.9 \pm 0.1$ & $3.9 \pm 0.5$ \\
\hline $8 \mathrm{i}$ & $c-\operatorname{Pr}$ & $\mathrm{C} 8$ & $1.3 \pm 0.2$ & $6.8 \pm 1.3$ \\
\hline 9a & $n$-Pr & C6 & $4.9 \pm 0.5$ & $10.7 \pm 1.1$ \\
\hline $9 b$ & i-Pr & C6 & $5.8 \pm 0.7$ & $7.7 \pm 0.8$ \\
\hline $9 c$ & $c-\operatorname{Pr}$ & C6 & $8.9 \pm 0.9$ & $9.8 \pm 0.8$ \\
\hline 9d & $n$-Pr & $\mathrm{C} 7$ & $3.1 \pm 0.3$ & $12.4 \pm 1.1$ \\
\hline $9 e$ & i-Pr & $\mathrm{C} 7$ & $10.6 \pm 0.9$ & $>25$ \\
\hline 9f & $c-\operatorname{Pr}$ & C7 & $5.2 \pm 0.6$ & $22.5 \pm 1.9$ \\
\hline $9 \mathrm{~g}$ & $n$-Pr & $\mathrm{C} 8$ & $4.9 \pm 0.5$ & $2.3 \pm 0.3$ \\
\hline $9 \mathrm{~h}$ & i-Pr & $\mathrm{C} 8$ & $4.0 \pm 0.4$ & $1.5 \pm 0.2$ \\
\hline $9 \mathrm{i}$ & $c-\operatorname{Pr}$ & $\mathrm{C} 8$ & $4.6 \pm 0.5$ & $2.2 \pm 0.2$ \\
\hline $10 a$ & $n$-Pr & - & NA & $13.7 \pm 2.0$ \\
\hline 10b & i-Pr & - & $1.1 \pm 0.1$ & $>25$ \\
\hline 10c & $c-\operatorname{Pr}$ & - & $6.8 \pm 1.0$ & $11.5 \pm 1.5$ \\
\hline $11 \mathrm{a}$ & $n$-Pr & - & NA & $>25$ \\
\hline $11 b$ & i-Pr & - & NA & $>25$ \\
\hline $11 \mathrm{c}$ & $c$-Pr & - & $>25$ & $>25$ \\
\hline $12 a$ & - & C6 & $6.5 \pm 0.9$ & $>25$ \\
\hline $12 b$ & - & C7 & $5.1 \pm 1.7$ & $>25$ \\
\hline $12 \mathrm{c}$ & - & $\mathrm{C} 8$ & $1.9 \pm 0.3$ & $>5.8 \pm 0.7$ \\
\hline 13a & - & C6 & $2.5 \pm 0.3$ & $5.6 \pm 0.7$ \\
\hline $13 b$ & - & $\mathrm{C} 7$ & $4.3 \pm 0.4$ & $9.4 \pm 0.9$ \\
\hline $13 c$ & - & $\mathrm{C} 8$ & $2.3 \pm 0.2$ & $1.8 \pm 0.3$ \\
\hline $14 a$ & - & - & NA & $12.7 \pm 2.0$ \\
\hline $15 a$ & - & - & $>25$ & $>25$ \\
\hline Resveratrol & - & - & $1.1 \pm 0.1$ & $15.3 \pm 1.9$ \\
\hline Curcumin & - & - & $3.3 \pm 0.4$ & $9.9 \pm 0.4$ \\
\hline
\end{tabular}

${ }^{a} \mathrm{IC}_{50}$ values were calculated using the ThT-based fluorescence spectroscopy assay (excitation $=440 \mathrm{~nm}$, emission $=490 \mathrm{~nm}$ ). ${ }^{b}$ Values are mean of triplicate readings for three independent experiments. $\mathrm{NA}=$ not active.

inhibitor $\left(\mathrm{IC}_{50} \sim 1.1 \mu \mathrm{M}\right)$. In the next step, the impact of a tertiary dimethylamine moiety at the C2-position was investigated. The presence of a $\mathrm{C} 4$ phenethylamine, increased potency toward $\mathrm{A} \beta 40$ 12a-c; $6-\mathrm{Cl}<7-\mathrm{Cl}<8-\mathrm{Cl}$ while only $12 \mathrm{c}$ was active toward $A \beta 42$. On the other hand, with a 3,4-dimethoxyphenethylamine at the $\mathrm{C} 4$ position, potency toward $\mathrm{A} \beta 40$ ranged from $\sim 2-4 \mu \mathrm{M}$ with chlorine placement at C6 being equipotent to $\mathrm{C} 8$ placement. The $\mathrm{A} \beta 42$ aggregation inhibitory potency increased from 7-Cl $\left(\mathbf{1 3 b}, \mathrm{IC}_{50} \sim 9.4 \mu \mathrm{M}\right)$ to $6-\mathrm{Cl}(13 \mathrm{a}$, $\left.\mathrm{IC}_{50} \sim 5.6 \mu \mathrm{M}\right)$ to $8-\mathrm{Cl}\left(\mathbf{1 3 c}, \mathrm{IC}_{50} \sim 1.8 \mu \mathrm{M}\right)$. Combining the $\mathrm{C} 2$ dimethylamine group with a $\mathrm{C} 4$ phenethylamine or 3,4-dimethoxyphenethylamine on a pyrido[3,2- $d]$ pyrimidine scaffold resulted in either weak or no inhibition of $A \beta$ aggregation (compounds 14a and 15a, Table 1). With respect to the $A \beta$ aggregation inhibition SAR, $\sim 22 \%$ of the derivatives screened surpassed the activity level of curcumin toward $A \beta 40$, while $\sim 44 \%$ surpassed the activity level of curcumin toward $A \beta 42$.
Derivative 8h (8-chloro- $N^{2}$-isopropyl- $N^{4}$-phenethylquinazoline2,4-diamine) was the most potent $\mathrm{A} \beta 40$ aggregation inhibitor $\left(\mathrm{IC}_{50} \sim 900 \mathrm{nM}\right)$, while $9 \mathrm{~h}$ (8-chloro- $N^{4}$-(3,4-dimethoxyphenethyl)- $N^{2}$-isopropylquinazoline-2,4-diamine) was the most potent $\mathrm{A} \beta 42$ aggregation inhibitor $\left(\mathrm{IC}_{50} \sim 1.5 \mu \mathrm{M}\right)$.

The ThT-based $A \beta 40$ aggregation kinetics data in the presence of the most active inhibitors ( $\mathbf{8 h}$ and $\mathbf{1 0 b}$ for $\mathrm{A} \beta 40$ ) is shown in Fig. 2. This reveals that, their modes of aggregation inhibition do differ from one another. As seen in Fig. 2 (panel A), $\mathbf{8 h}$ was exhibiting a concentration-dependent reduction in the aggregation with complete inhibition of $A \beta 40$ aggregation seen at $25 \mu \mathrm{M}$. On the other hand, 10b (Fig. 2, panel C) was also exhibiting a concentration-dependent reduction in aggregation. In addition, unlike compound $\mathbf{8 h}$, it was able to delay the onset of aggregation by delaying the lag phase further. Investigating the $A \beta$ morphology by TEM imaging further confirms the ability of both compounds $\mathbf{8 h}$ and $\mathbf{1 0 b}$ to prevent $A \beta$ aggregation (Fig. 2). Analysis of the $A \beta 42$ aggregation kinetics in the presence of the most active inhibitors ( $9 h$ and $13 \mathrm{c}$ for $\mathrm{A} \beta 42$, Fig. 2) revealed similar observations. Both derivatives, which were nearly equipotent against A $\beta 42$ aggregation, shared similar modes of action. As seen in Fig. 2 (panel B), 9h was able to reduce the overall load of $A \beta 42$ fibril formation in a concentration dependent manner with almost complete inhibition seen at $25 \mu \mathrm{M}$. A similar trend was seen with 13c (Fig. 2, panel D). Furthermore, TEM morphology studies corroborate aggregation kinetics data observed (Fig. 2).

The molecular docking study of best two A $\beta 40$ aggregation inhibitors, $\mathbf{8 h}$ and $\mathbf{1 0 b}$, in the $A \beta$ dimer model (Fig. 3, panel A) derived from the solution structure of $A \beta$ fibrils ${ }^{16}$ (pdb id:2LMN) indicated that both the 8-chloroquinazoline and the pyrido[3,2] pyrimidine templates were oriented between $\mathrm{C}$ - and $\mathrm{N}$-terminal region whereas the $\mathrm{C} 4$-phenethylamine substituent was closer to the turn region Asp23-Gly29 (distance $~ 6-8 \AA$ ). Hydrophobic interactions were the dominating force involved. In the pyrido $[3,2-d]$ pyrimidine compound $\mathbf{1 0 b}$, the presence of an additional ring nitrogen (N5) led to a hydrogen bonding contact with the amide backbone of Val24 (distance $\sim 3 \AA$ ). In the fibril model, Fig. 3, panel B, both $\mathbf{8 h}$ and $\mathbf{1 0 b}$ had similar binding modes where the C4-phenethylamine group was oriented toward the center region of the fibril core (Ile32-Met35, distance $\sim 5-8 \AA$ ). Both core templates were undergoing hydrophobic interactions with Ile31-Val38 (distance $\sim 5-8 \AA$ ) at the C-terminal end. These studies support the ability of $\mathbf{8 h}$ and $\mathbf{1 0 b}$ to reduce fibril aggregation.

\subsection{Inhibition of cholinesterases}

With respect to cholinesterase inhibition, the SAR data is shown in Table 2. While examining the first cluster of C4 phenethylamine-based chloroquinazolines $(\mathbf{8 a}-\mathbf{i})$, it became evident that chlorine placement at either C6, C7 or C8 was able to modulate the ChE inhibitory activity with 7-Cl exhibiting better ChE inhibition. The ChE inhibition can be ranked as 7-Cl $>6-\mathrm{Cl}>8-\mathrm{Cl}$ with respect to both ChEs. Most noteworthy was the outcome from 8e $\left(\mathrm{AChE} \mathrm{IC}_{50} \sim 6.6 \mu \mathrm{M}\right.$, BuChE $\left.\mathrm{IC}_{50} \sim 100 \mathrm{nM}\right)$, which was the most potent AChE inhibitor in this group, and 
(A) 35$]=\mathrm{ThT}$

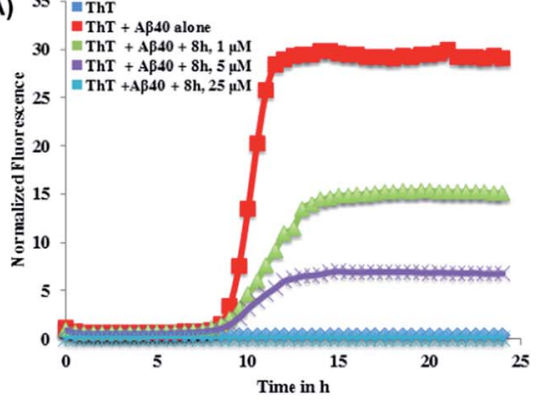

(C) $35=\mathrm{ThT}$

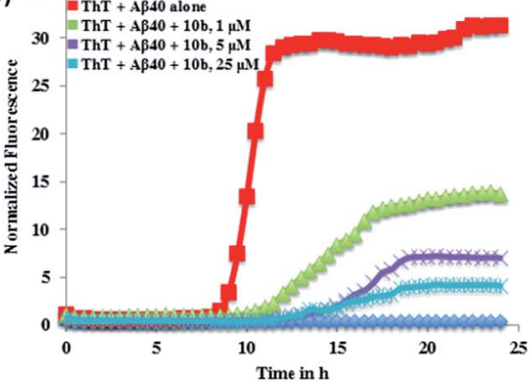

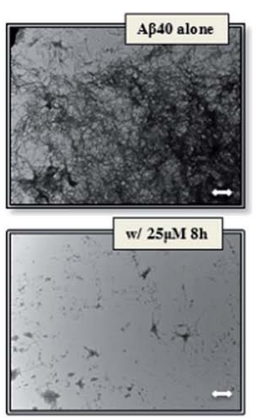

B)
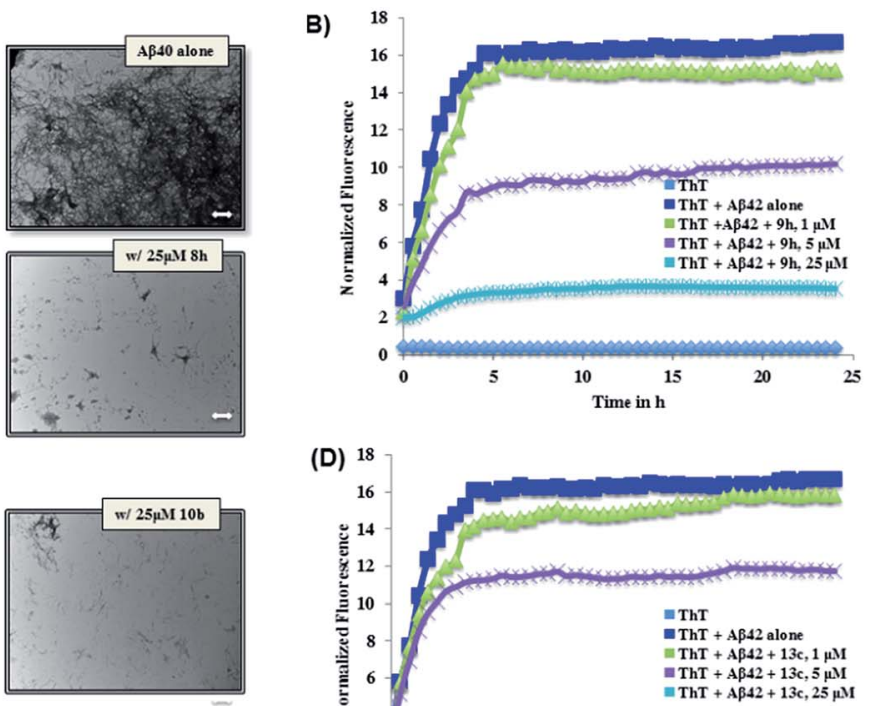

(D) 18

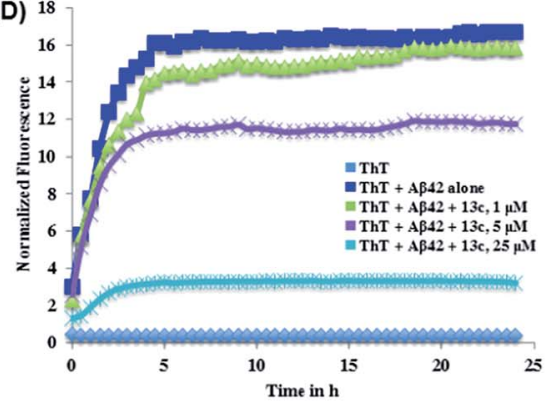

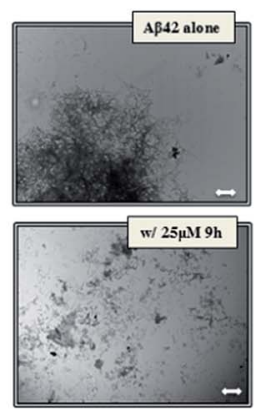

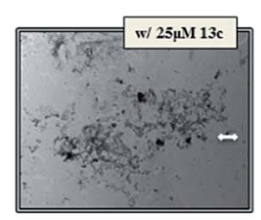

Fig. 2 A $440 / A \beta 42(5 \mu M)$ aggregation kinetics study with or without 1,5 or $25 \mu \mathrm{M}$ of $8 \mathrm{~h}$ (panel A), 9h (panel B), 10b (panel C) or 13c (panel D) along with corresponding TEM morphology in the presence of $25 \mu \mathrm{M}$ of $8 \mathrm{~h}, 9 \mathrm{~h}, 10 \mathrm{~b}$ or $13 \mathrm{c}$. Aggregation kinetics were monitored by ThT-fluorescence spectroscopy (excitation $=440 \mathrm{~nm}$, emission $=490 \mathrm{~nm}$ ) for $24 \mathrm{~h}$ at $37^{\circ} \mathrm{C}$ in phosphate buffer at pH 7.4. TEM image scale: white bars represent $500 \mathrm{~nm}$.

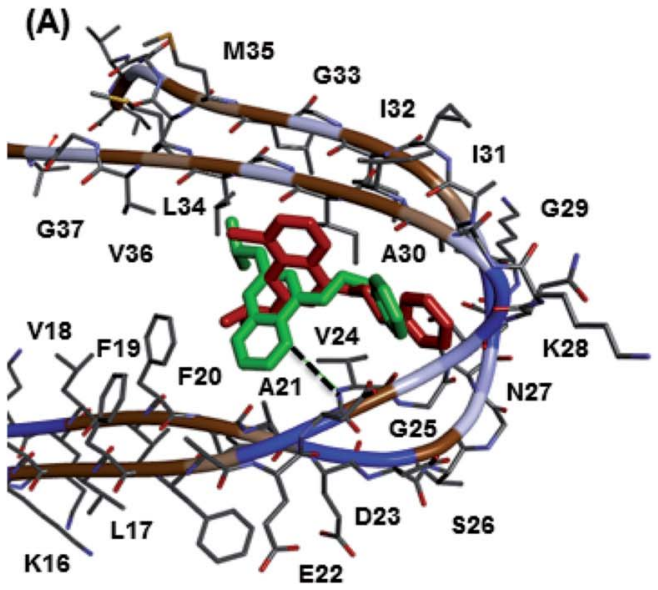

(B)

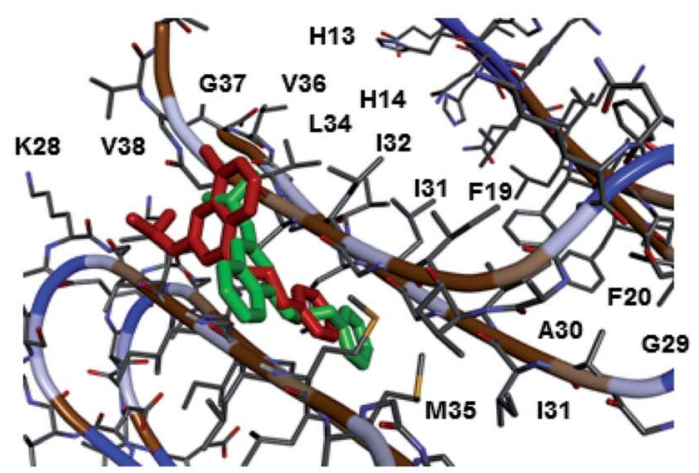

Fig. 3 A $\beta$ molecular docking studies. Binding modes of the quinazoline compound $8 \mathrm{~h}(\mathrm{red}$ ) and pyrido[3,2- $d$ ] pyrimidine compound $10 \mathrm{~b}$ (green) in $A \beta$-dimer model (panel A) and A $\beta$-fibril model (panel B). Hydrogen atoms were removed for clarity.

was the most potent BuChE inhibitor overall (about 36-fold more potent compared to donepezil, $\mathrm{IC}_{50}=3.60 \mu \mathrm{M}$ ). The addition of the 3,4-dimethoxyphenethyl substituent in the second cluster of derivatives (9a-i) exhibited similar AChE inhibition range as per compounds 8a-i. However, it was detrimental for BuChE inhibition, although one key derivative stood out from the pack (9e, BuChE $\left.\mathrm{IC}_{50} \sim 4 \mu \mathrm{M}\right)$ and was equivalent to donepezil. It is interesting to point out that both compounds 8e and 9e that exhibited significant BuChE inhibition possessed a $\mathrm{C} 2$ isopropylamine substituent which promoted BuChE inhibition. Replacing the quinazoline template with a pyrido[3,2- $d]$ pyrimidine template $(\mathbf{1 0 a}-\mathbf{c}$ and 11a-c), led to weak or no inhibitory activity toward BuChE. With respect to AChE inhibition, they were on par with the chloroquinazolines (8a-i and $\mathbf{9 a - i})$ with activity range $\mathrm{AChE} \mathrm{IC}_{50} \sim 7-$ $8 \mu \mathrm{M}$, Table 2. The incorporation of a $N, N$-dimethylamine at the $\mathrm{C} 2$ position was explored to investigate the role of a tertiary amine instead of a secondary amine toward ChE inhibition (12a-c and 13a-c). The chlorine placement played a role as $\mathbf{1 2 b}$ (7-Cl, BuChE $\left.\mathrm{IC}_{50} \sim 1.5 \mu \mathrm{M}\right)$ was $\sim 3.6$-fold more potent compared to its 6-chloro isomer (12a). In addition, 12b was more potent compared to compound 13b $\left(\mathrm{BuChE} \mathrm{IC}_{50}>50 \mu \mathrm{M}\right)$. 
Table 2 Cholinesterase inhibition (AChE and BuChE) of quinazolines $(8,9,12$ and 13$)$ and pyrido[3,2-d]pyrimidines $(10,11,14$ and 15)

\begin{tabular}{|c|c|c|c|c|}
\hline \multirow[b]{2}{*}{ Compd } & \multirow[b]{2}{*}{$\mathrm{R}^{1}$} & \multirow{2}{*}{$\begin{array}{l}\text { Chloride } \\
\text { substitution }\end{array}$} & \multicolumn{2}{|l|}{$\mathrm{IC}_{50}{ }^{a}(\mu \mathrm{M})$} \\
\hline & & & $h \mathrm{AChE}$ & $h$ BuChE \\
\hline $8 a$ & $n$-Pr & C6 & $8.9 \pm 0.6$ & $4.8 \pm 0.3$ \\
\hline $8 b$ & i-Pr & C6 & $8.7 \pm 0.5$ & $1.5 \pm 0.1$ \\
\hline $8 c$ & $c-\operatorname{Pr}$ & C6 & $8.7 \pm 0.9$ & $9.1 \pm 0.7$ \\
\hline $8 d$ & $n$-Pr & $\mathrm{C} 7$ & $7.2 \pm 0.7$ & $4.4 \pm 0.4$ \\
\hline $8 e$ & i-Pr & $\mathrm{C} 7$ & $6.6 \pm 0.6$ & $0.1 \pm 0.02$ \\
\hline $8 f$ & $c-\mathrm{Pr}$ & $\mathrm{C} 7$ & $7.3 \pm 0.6$ & $3.5 \pm 0.4$ \\
\hline $8 g$ & $n$-Pr & $\mathrm{C} 8$ & $7.7 \pm 0.7$ & $6.0 \pm 0.6$ \\
\hline $8 \mathrm{~h}$ & i-Pr & C8 & $8.6 \pm 0.9$ & $2.6 \pm 0.2$ \\
\hline $8 \mathrm{i}$ & $c-\mathrm{Pr}$ & $\mathrm{C} 8$ & $7.6 \pm 0.7$ & $10.9 \pm 0.9$ \\
\hline $9 a$ & $n$-Pr & C6 & $6.2 \pm 0.4$ & $>50$ \\
\hline $9 b$ & i-Pr & C6 & $6.8 \pm 0.7$ & $20.3 \pm 1.5$ \\
\hline $9 c$ & $c-\mathrm{Pr}$ & C6 & $8.0 \pm 0.7$ & $>50$ \\
\hline 9d & $n-\operatorname{Pr}$ & $\mathrm{C} 7$ & $7.2 \pm 0.7$ & $>50$ \\
\hline $9 e$ & i-Pr & $\mathrm{C} 7$ & $7.9 \pm 0.8$ & $3.9 \pm 0.3$ \\
\hline 9f & $c-\mathrm{Pr}$ & C7 & $8.7 \pm 0.8$ & $>50$ \\
\hline $9 \mathrm{~g}$ & $n$-Pr & $\mathrm{C} 8$ & $6.5 \pm 0.5$ & $>50$ \\
\hline $9 \mathrm{~h}$ & i-Pr & $\mathrm{C} 8$ & $6.8 \pm 0.7$ & $19.3 \pm 1.1$ \\
\hline $9 \mathrm{i}$ & $c-\mathrm{Pr}$ & $\mathrm{C} 8$ & $6.6 \pm 0.7$ & $>50$ \\
\hline $10 a$ & $n-\mathrm{Pr}$ & - & $8.1 \pm 0.8$ & $30.3 \pm 2.8$ \\
\hline $10 \mathrm{~b}$ & i-Pr & - & $7.8 \pm 0.8$ & $29.3 \pm 2.0$ \\
\hline $10 \mathrm{c}$ & $c-\mathrm{Pr}$ & - & $7.6 \pm 0.6$ & $>50$ \\
\hline $11 a$ & $n-\operatorname{Pr}$ & - & $7.2 \pm 0.8$ & $>50$ \\
\hline $11 b$ & i-Pr & - & $7.4 \pm 0.7$ & $>50$ \\
\hline $11 \mathrm{c}$ & $c-\operatorname{Pr}$ & - & $7.2 \pm 0.5$ & $>50$ \\
\hline $12 a$ & - & C6 & $7.7 \pm 0.8$ & $5.4 \pm 0.6$ \\
\hline $12 b$ & - & $\mathrm{C} 7$ & $5.8 \pm 0.7$ & $1.5 \pm 0.1$ \\
\hline $12 \mathrm{c}$ & - & $\mathrm{C} 8$ & $7.5 \pm 0.8$ & $>50$ \\
\hline $13 a$ & - & C6 & $7.2 \pm 0.7$ & $31.2 \pm 3.4$ \\
\hline $13 b$ & - & $\mathrm{C} 7$ & $13.4 \pm 1.1$ & $>50$ \\
\hline $13 c$ & - & C8 & $8.1 \pm 0.8$ & $>50$ \\
\hline $14 a$ & - & - & $6.8 \pm 0.7$ & $>50$ \\
\hline $15 a$ & - & - & $6.7 \pm 0.5$ & $>50$ \\
\hline Donepezil & - & - & $0.03 \pm 0.002$ & $3.6 \pm 0.4$ \\
\hline Galantamine & - & - & $2.6 \pm 0.6$ & $>50$ \\
\hline
\end{tabular}

${ }^{a} \mathrm{IC}_{50}$ values were an average $\pm \mathrm{SD}$ of triplicate readings for two to three independent experiments.

This trend also extended to the AChE profiles, where 12b (AChE IC $_{50} \sim 5.8 \mu \mathrm{M}$ ) was $\sim 2.3$-fold more potent compared to $13 \mathbf{b}$, it was also $\sim 1$.3-fold more potent compared to its 6- and 8-chloro isomers (12a and 12c). These studies show that combining the $\mathrm{N}, \mathrm{N}$-dimethylamine group at $\mathrm{C} 2$ with phenethylamine or 3,4dimethoxyphenethylamine on a pyrido[3,2- $d]$ pyrimidine scaffold resulted in equipotent and selective AChE inhibition (14a and 15a, AChE $\mathrm{IC}_{50} \sim 6.7 \mu \mathrm{M}$, BuChE $\mathrm{IC}_{50}>50 \mu \mathrm{M}$, Table 2). The quinazoline derivative $\mathbf{8 e}$ (7-chloro- $N^{2}$-isopropyl- $N^{4}$ phenethylquinazoline-2,4-diamine) was the most potent BuChE inhibitor with an $\mathrm{IC}_{50} \sim 100 \mathrm{nM}$, while 12b (7-chloro- $N^{2}, N^{2}$ dimethyl- $N^{4}$-phenethylquinazoline-2,4-diamine) was the most potent AChE inhibitor with an $\mathrm{IC}_{50} \sim 5.8 \mu \mathrm{M}$.

The binding interaction of quinazoline derivatives was investigated by using the X-ray crystal structures of human AChE (pdb id:1B41) and BuChE (pdb id:1P0I) enzymes. ${ }^{17,18}$ The binding modes of two best quinazoline based AChE inhibitors 9a and 12b in hAChE (Fig. 4, panel A) revealed quite similar

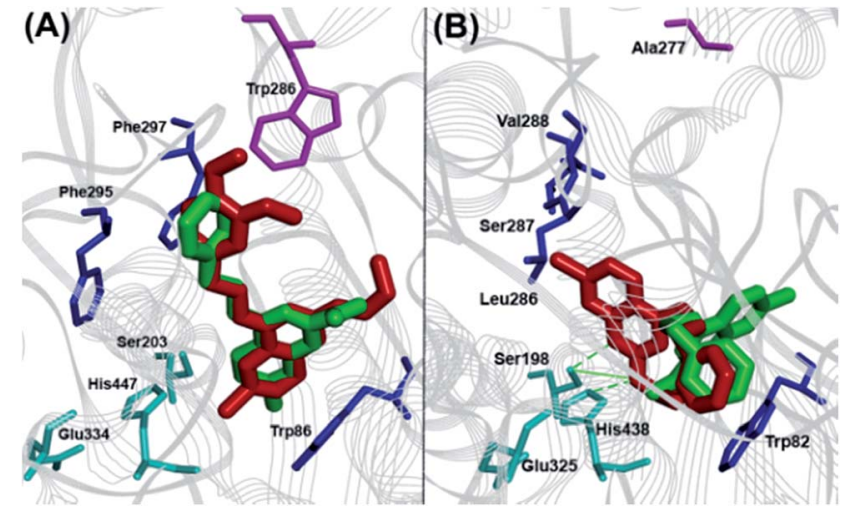

Fig. 4 Cholinesterase molecular docking studies. Panel (A): Binding modes of 9a (red) and 12b (green) in hAChE. Panel (B): Binding modes of $8 \mathrm{e}$ (red) and $12 \mathrm{~b}$ (green) in $h \mathrm{BuChE}$. Hydrogen atoms removed for clarity.

binding interactions, explaining their near-equipotent inhibition of the AChE $\left(\mathrm{IC}_{50} \sim 6 \mu \mathrm{M}\right)$. In both derivatives, the 7chloroquinazoline ring scaffold was stacked parallel against Trp86 (distance 4-6 ̊) and the C4-benzylamino groups were extending from the catalytic site toward the peripheral anionic site (PAS), where the 3,4-dimethoxy moiety of compound 9a was undergoing favorable interactions with Trp286 (distance $\sim 3-4$ A). The C6 and C7 chlorine atoms were oriented toward the catalytic triad (distance $\sim 6-8 \AA$ ), while the C2-alkylamine groups underwent hydrophobic interactions with Trp86 (distance $\sim 3-5 \AA$ ). The binding orientation of compounds 8e and 12b that exhibited superior inhibitory potency toward BuChE was quite different (Fig. 4, panel B). The most potent BuChE inhibitor 8e underwent three hydrogen-bonding interactions centered around the $\mathrm{C} 2$ isopropylamine- $\mathrm{NH}$, the 7chloroquinazoline- $N 1$ with His447 and Ser203 duo (distance 2.5-3.5 $\AA$ ). The core ring scaffold was also oriented in the catalytic triad, with the $\mathrm{C} 7$ chlorine oriented toward the acyl pocket (Leu286-Val288, distance $\sim 4-5$ A). The C4phenethylamine substituent was oriented perpendicular to Trp82 (Fig. 4, panel B). On the other hand, derivative $\mathbf{1 2 b}$ had its core scaffold and C4-phenethylamine substituent directly interacting with Trp82 (distance $\sim 3-4 \AA$ ), while the $N, N$-dimethylamine was oriented toward the catalytic triad (distance $\sim 4-$ 5 A) which explains their superior inhibition profile.

\subsection{Iron chelation properties}

The presence of an additional ring nitrogen in the pyrido[3,2- $d]$ pyrimidine class of compounds (10a-c, 11a-c, 14a and 15a) provides a chelation center. ${ }^{19,20}$ Due to the role of iron in promoting oxidative stress in $\mathrm{AD}^{21-23}$ and its contribution in the formation of neurotoxic $\mathrm{A} \beta$ plaques and neurofibrillary tangles (NFTs), we assessed the $\mathrm{Fe}^{2+}$-chelation potential of the pyrido $[3,2-d]$ pyrimidines (Table 3 ) in ferrozine based assay. The known iron chelators clioquinol and deferroxamine were used as reference agents. These studies show that, the $\mathrm{C} 4$ phenethylamine substituted compounds 10a-c exhibited better chelation capacity compared to their $\mathrm{C4}$ 3,4- 
Table 3 Iron $\left(\mathrm{Fe}^{2+}\right)$ chelation studies of pyrido[3,2- $d$ ]pyrimidines

\begin{tabular}{|c|c|c|c|}
\hline Compd & $\mathrm{R}$ & $\mathrm{R}^{1}$ & $\begin{array}{l}\% \mathrm{Fe}^{2+} \\
\text { Chelation }^{a}\end{array}$ \\
\hline $10 \mathrm{a}$ & Phenethyl & $n$-Pr & $29.3 \pm 4.3$ \\
\hline 10b & Phenethyl & $\mathrm{i}-\mathrm{Pr}$ & $23.6 \pm 4.0$ \\
\hline 10c & Phenethyl & $c-\operatorname{Pr}$ & $37.0 \pm 5.6$ \\
\hline $11 \mathrm{a}$ & 3,4-DiOMe-phenethyl & $n-\mathrm{Pr}$ & $24.1 \pm 3.6$ \\
\hline 11b & 3,4-DiOMe-phenethyl & $\mathrm{i}-\mathrm{Pr}$ & $21.8 \pm 3.3$ \\
\hline 11c & 3,4-DiOMe-phenethyl & $c-\mathrm{Pr}$ & $26.7 \pm 4.0$ \\
\hline $14 a$ & Phenethyl & - & $22.9 \pm 3.4$ \\
\hline $15 a$ & 3,4-DiOMe-phenethyl & - & $23.0 \pm 3.0$ \\
\hline Clioquinol & - & - & $39.0 \pm 5.8$ \\
\hline Deferoxamine & - & - & $86.7 \pm 11.0$ \\
\hline
\end{tabular}

dimethoxyphenethyl dimethoxyphenethylamine counterparts 11a-c, 14a and 15a (inactive at $50 \mu \mathrm{M}$ ).

Overall, these pyrido[3,2- $d]$ pyrimidine compounds exhibited weak to moderate $(22-37 \%$ chelation) iron-chelation capacity. Interestingly, the presence of a C2 cyclopropyl substituent provided the best chelation capacity compared to other $\mathrm{C} 2$ substituents explored with compound 10c exhibiting equipotent iron-chelation capability $(37 \%$ chelation at $50 \mu \mathrm{M})$ compared to the reference agent clioquinol (39\% inhibition at $50 \mu \mathrm{M}$, Table 3). More significantly, the corresponding quinazoline class of compounds did not exhibit any iron-chelation capacity highlighting the requirement of a pyrido $[3,2-d]$ pyrimidine ring scaffold to display iron-chelation properties.

\section{Conclusions}

In summary, we synthesized and optimized the structure of quinazoline based ring scaffold as multi-targeting agents aimed at the amyloid, cholinergic, and oxidative stress pathways of $\mathrm{AD}$ pathophysiology. A number of agents synthesized exhibited dual $A \beta$, ChE inhibition and iron-chelation capacity. The SAR acquired shows that compound $\mathbf{8 h}$ was the most potent $\mathrm{A} \beta 40$ aggregation inhibitor $\left(\mathrm{IC}_{50}=900 \mathrm{nM}\right)$ and compound $8 \mathrm{e}$ provided dual $\mathrm{A} \beta\left(\mathrm{IC}_{50} \mathrm{~A} \beta 40=6.1 \mu \mathrm{M} ; \mathrm{A} \beta 42 \mathrm{IC}_{50}=7.2 \mu \mathrm{M}\right)$ and ChE inhibition $\left(\mathrm{IC}_{50} \mathrm{AChE}=6.6 \mu \mathrm{M}\right.$; BuChE $\left.\mathrm{IC}_{50}=100 \mathrm{nM}\right)$. The presence of a pyrido[3,2- $d]$ pyrimidine bioisostere instead of a quinazoline was essential to exhibit iron-chelation properties (22-37\% chelation) with compounds $10 \mathrm{~b}$ and 10c exhibiting multi-targeting activity toward $\mathrm{A} \beta, \mathrm{ChE}$ and iron-chelation properties. The data presented herein highlights the dual anti-A $\beta 40 / \beta 42$ aggregation, ChE inhibition, and metal-chelation capabilities of quinazoline and pyrido[3,2- $d]$ pyrimidine class of compounds as multi-targeting agents to treat $\mathrm{AD}$.

\section{Materials and methods}

\subsection{General information}

All chemicals and reagents used were purchased from either Sigma-Aldrich, USA or Alfa Aesar, USA and was used without further purification. Melting points were determined using a Fisher-Johns melting point apparatus and are uncorrected. ${ }^{1} \mathrm{H}$ NMR (300 MHz) and ${ }^{13} \mathrm{C}$ NMR spectra (100 MHz) were recorded on a Bruker Avance NMR spectrometer in DMSO- $d_{6}$. Coupling constants ( $J$ values) were recorded in hertz $(\mathrm{Hz})$ and the following abbreviations were used to represent multiplets of NMR signals: $\mathrm{s}=$ singlet, $\mathrm{d}=$ doublet, $\mathrm{t}=$ triplet, $\mathrm{m}=$ multiplet, br $=$ broad. Carbon multiplicities $\left(\mathrm{C}, \mathrm{CH}, \mathrm{CH}_{2}\right.$ and $\left.\mathrm{CH}_{3}\right)$ were assigned by DEPT 90/135 experiments. Low-resolution mass spectra (LRMS) was obtained using an Agilent 6100 series single quad LCMS whereas high-resolution mass spectra (HRMS) were recorded on a Thermo Scientific Q Exactive ${ }^{\mathrm{TM}}$ mass spectrometer with an ESI source, Department of Chemistry, University of Waterloo. Compound purity was assessed ( $~ 95 \%$ purity) using an Agilent 6100 series single quad LCMS equipped with an Agilent $1.8 \mu \mathrm{m}$ Zorbax Eclipse Plus C18 $(2.1 \times 50 \mathrm{~mm})$ running $50: 50$ water/ACN with $0.1 \% \mathrm{FA}$ at a flow rate of $0.5 \mathrm{~mL} \mathrm{~min} \mathrm{~m}^{-1}$ with detection at $254 \mathrm{~nm}$ by UV. Compounds 3a-d and $4 \mathbf{a}$ were previously reported. ${ }^{24-26}$

4.1.1 General procedure for the synthesis of compounds 3a-d. These compounds were synthesized as per previously reported method. ${ }^{2426}$ In a $350 \mathrm{~mL}$ round pressure vial 16-18 g urea was heated at $150-155{ }^{\circ} \mathrm{C}$ till it melted. To the liquid urea solution 0.1 eq. of $1 \mathrm{a}$, or $\mathbf{1 b}$, or $1 \mathbf{c}$ or $1 \mathbf{d}$ was added. The pressure vial was sealed and heated at $150-155{ }^{\circ} \mathrm{C}$ for $2 \mathrm{~h}$, cooled to room temperature, followed by the addition of water $(100 \mathrm{~mL})$ after which the reaction mixture was heated at $100-105{ }^{\circ} \mathrm{C}$ for $1 \mathrm{~h}$. After cooling to room temperature, the reaction mixture was diluted with $\sim 80 \mathrm{~mL}$ EtOAc and washed with brine solution (50 $\mathrm{mL} \times 4$ ). The combined aqueous layers were washed with $\sim 35$ $\mathrm{mL}$ EtOAc, dried over $\mathrm{MgSO}_{4}$ and the organic solvent was removed in vacuo. The solid obtained (compounds 2a-d) was straightaway carried to the next step (yield 70-85\%) without further purification. In a $250 \mathrm{~mL} \mathrm{RBF}, 29.24 \mathrm{mmol}$ of either $2 \mathrm{a}$ or $2 \mathbf{b}$ or $2 \mathbf{c}$ or $\mathbf{2 d}$ was suspended in $25 \mathrm{~mL}$ of anhydrous toluene and allowed to stir on an ice bath. To this, 5 eq. of $\mathrm{POCl}_{3}$ was added in small aliquots followed by the slow addition of 5 eq. of DEA. The solution was kept on the ice bath for $10 \mathrm{~min}$ before moving to room temperature and allowed to stir for $1 \mathrm{~h}$ prior to refluxing at $105-110{ }^{\circ} \mathrm{C}$ for $14-16 \mathrm{~h}$. Upon cooling to room temperature, the reaction mixture was added in small aliquots to a double-ice-water bath while stirring. The quenching solution was left stirring at room temperature for $5 \mathrm{~h}$ before vacuum filtering the yellowish-grey precipitate. The precipitate was stirred for $1 \mathrm{~h}$ in saturated $\mathrm{NaHCO}_{3}$ solution and was filtered. This neutralization process was carried out 2-3 times until the bicarbonate solution maintains a neutral to slight basic $\mathrm{pH}$. The final precipitate was dissolved in DCM and purified by a silica gel column chromatography using $100 \%$ DCM as the eluent to afford white to light grey solids 3a-d (65-80\%).

4.1.2 General procedure for the synthesis of compounds 4a-c, 5a-c, 6a and 7a. These compounds were synthesized as per previously reported method. ${ }^{27,28}$ To a $30 \mathrm{~mL}$ solution of ethanol in a $100 \mathrm{~mL}$ round-bottom flask on ice, 21.46$25.13 \mathrm{mmol}$ of either $\mathbf{3 a}$ or $\mathbf{3 b}$ or $\mathbf{3 c}$ or $\mathbf{3 d}$ was added followed by slow addition of 1.3 eq. (27.90-32.66 mmol) of the corresponding primary amine. Contents were stirred on an ice bath 
while 2.0 eq. of diisopropyl-ethylamine (DIPEA, 42.92-50.25 mmol) was added in drop wise fashion. The solution was then heated at $80-85{ }^{\circ} \mathrm{C}$ under reflux for $3-4 \mathrm{~h}$. The reaction contents were cooled to room temperature and precipitated residues were vacuum-filtered with EtOAc. The organic supernatant was concentrated in vacuo followed by two rounds of extraction using EtOAc and saturated brine solution $(40-50 \mathrm{~mL}$ each respectively). The combined organic layers were dried over $\mathrm{MgSO}_{4}$, evaporated in vacuo and purified (1-2 times) using silica gel column chromatography with 5:1 EtOAc: $\mathrm{MeOH}$ as the elution solvent to afford $\mathbf{4 a - c , 5 a - c , ~} \mathbf{6 a}$ and $7 \mathbf{a}$ as white to beige solids with yields ranging from $75-90 \%$.

4.1.3 General procedure for the synthesis of compounds 8a-i, 9a-i, 10a-c, 11a-c, 12a-c, 13a-c, 14a and 15a. The target compounds were synthesized as per previously reported method. ${ }^{12,28}$ Briefly in a $50 \mathrm{~mL}$ pressure vial (PV), $0.25 \mathrm{~g}$ of 2,6dichloro, 2,7-dichloro or 2,8-dichloro- $N$-substituted quinazolin4-amine or 2-chloro- $N$-substituted pyrido[3,2- $d$ ]pyrimidine-2,4diamine $(\sim 0.66-0.83 \mathrm{mmol})$ was combined with 2 eq. $(\sim 1.32-$ $1.66 \mathrm{mmol}$ ) of primary amine (methyl-, ethyl-, n-propyl-, isopropyl- or cyclopropylamine) or dimethylamine which was dissolved in $5 \mathrm{~mL}$ of 1,4-dioxane followed by the addition of 3 eq. of DIPEA ( 1.98-2.40 mmol). Pressure vial was sealed and stirred in an oil bath at $150-155{ }^{\circ} \mathrm{C}$ for $2 \mathrm{~h}$. Upon completion and cooling to room temperature, the reaction mixture was diluted with $\sim 40 \mathrm{~mL}$ of EtOAc and washed with brine solution $(25 \mathrm{~mL} \times$ 2 ). The combined aqueous layer was washed with $\sim 25 \mathrm{~mL}$ of EtOAc. The combined EtOAc layers were dried over $\mathbf{M g S O}_{4}$ before removing EtOAc in vacuo to yield a solid product that was purified by silica gel column chromatography using 5:1 EtOAc: $\mathrm{MeOH}$ as the eluent to afford pale yellow to brown solids (yield $\sim 68-78 \%$ ).

\subsection{Experimental procedure for cholinesterase (hAChE/ hBuChE) inhibition}

Quinazoline and pyrido[3,2- $d]$ pyrimidine derivatives $(\mathbf{8 a}-\mathbf{i}, \mathbf{9 a}-\mathbf{i}$, 10a-c, 11a-c, 12a-c, 13a-c, 14a and 15a) were evaluated for ChE inhibitory activity using Ellman's method. ${ }^{12,15,29}$ The test compounds compete with substrates acetylthiocholine iodide (ATChI) and $S$-butyrylthiocholine iodide (BuTChI) for either human AChE (Sigma-Aldrich, St. Louis, MO) or human BuChE (Sigma-Aldrich, St. Louis, MO), respectively. Known ChE inhibitors donepezil and rivastigmine were used as reference agents for comparison. Quinazoline and pyrido[3,2- $d]$ pyrimidine derivatives were prepared in DMSO (maximum concentration used $1 \% \mathrm{v} / \mathrm{v}$ ) and $10 \mu \mathrm{L}$ each (0.001-25 $\mu \mathrm{M}$ final concentration range), was incubated for 5 minutes at room temperature with $160 \mu \mathrm{L}$ of $1.5 \mathrm{mM}$ DTNB, $50 \mu \mathrm{L} 0.22 \mathrm{U} \mathrm{mL}^{-1}$ AChE (in $50 \mathrm{~mm}$ Tris $\cdot \mathrm{HCl}, \mathrm{pH} 8.0,0.1 \% \mathrm{w} / \mathrm{v}$ bovine serum albumin, BSA) or $50 \mu \mathrm{L} 0.12 \mathrm{U} \mathrm{mL}^{-1} \mathrm{BuChE}$ (in $50 \mathrm{~mm}$ Tris $\cdot \mathrm{HCl}$, $\mathrm{pH} 8.0,0.1 \% \mathrm{w} / \mathrm{v}$ bovine serum albumin, BSA). After the incubation period, $30 \mu \mathrm{L}$ of ATChI $(15 \mathrm{mM}$, prepared in ultra pure water) or BuTChI (15 mM, prepared in ultra pure water) were added to 96-well plates. The ChE inhibition was measured at $412 \mathrm{~nm}$ wavelength using a microplate reader (BioTek Synergy $\mathrm{H} 1$ microplate reader) at various time intervals $(t=0,1,2,3,4$ and 5 min). Appropriate controls, without the test compounds and $\mathrm{ChE}$ were included. The inhibitory concentration $\left(\mathrm{IC}_{50}\right.$ values) was calculated from the concentration-inhibition dose response curve on a logarithmic scale based on two independent experiments run in triplicates.

\subsection{Experimental procedure for thioflavin $T$ based $A \beta$ aggregation kinetics}

The anti-A $\beta$ aggregation activity of test compounds $(\mathbf{8 a}-\mathbf{i}, \mathbf{9 a}-\mathbf{i}$, 10a-c, 11a-c, 12a-c, 13a-c, 14a and 15a), was evaluated using the ThT-based fluorescence assay. ${ }^{\mathbf{1 1}, \mathbf{1 4}}$ The $\mathrm{A} \beta 40$ and $\mathrm{A} \beta 42$ hexafluoro-2-propanol (HFIP) (rPeptide, Geogia, USA) stock solution was prepared by dissolving in $1 \% \mathrm{NH}_{4} \mathrm{OH}$ solution, to a $1 \mathrm{mg} \mathrm{mL}{ }^{-1}$ stock solution, followed by dilution to $50 \mu \mathrm{M}$ in phosphate buffer ( $215 \mathrm{mM}, \mathrm{pH}$ 7.4). Stock solutions of test compounds were prepared in DMSO, diluted in phosphate buffer ( $\mathrm{pH}$ 7.4), and were sonicated for $30 \mathrm{~min}$. The final DMSO concentration per each well was $1 \% \mathrm{v} / \mathrm{v}$ or lower. The ThT fluorescent dye stock solution $(15 \mu \mathrm{M})$ was prepared in $50 \mathrm{mM}$ glycine buffer ( $\mathrm{pH}$ 7.4). The aggregation kinetics assay was carried out using a Corning® 384-well flat, clear bottom black plates. Each well contains $44 \mu \mathrm{L}$ of ThT, 20-35 $\mu \mathrm{L}$ of phosphate buffer ( $\mathrm{pH} 7.4$ ), $8 \mu \mathrm{L}$ of test compounds in different concentrations $(1,5,10$ and $25 \mu \mathrm{M}$, final concentration) and $8 \mu \mathrm{L}$ of either $\mathrm{A} \beta 40$ or $\mathrm{A} \beta 42$ ( $5 \mu \mathrm{M}$ final concentration). The plate was incubated at $37{ }^{\circ} \mathrm{C}$ with a plate cover under shaking and fluorescence was measured every 5 min using a BioTek Synergy H1 microplate reader multimode plate reader (excitation $=440 \mathrm{~nm}$ and emission $=490 \mathrm{~nm}$ ) over a period of $24 \mathrm{~h}$. Appropriate control experiments that contain either $A \beta 40 / 42$ and test compound alone were evaluated. The known $A \beta$ aggregation inhibitors curcumin and resveratrol were used as reference agents. The $\mathrm{IC}_{50}$ value $(\mu \mathrm{M})$ was calculated using the equation $100 \%$ control - [(IFi-IFo)] where $100 \%$ control indicates no inhibitor, IFi and IFo are the fluorescence intensities in the presence and absence of ThT. The results were expressed as $\mathrm{IC}_{50}$ values $\pm \mathrm{SD}$ based on two separate experiments in triplicate measurements.

\subsection{Experimental procedure for transmission electron microscopy (TEM)}

In Costar 96-well, round-bottom plates were added $80 \mu \mathrm{L}$ of $215 \mathrm{mM}$ phosphate buffer, $20 \mu \mathrm{L}$ of $10 \times$ test compound dilutions ( $250 \mu \mathrm{M}$ - prepared in the same way as for the ThT assay) and $100 \mu \mathrm{L}$ of $\mathrm{A} \beta 40$ or $\mathrm{A} \beta 42$ respectively ( $50 \mu \mathrm{M}$ each). For the control wells, $2 \mu \mathrm{L}$ of DMSO and $18 \mu \mathrm{L}$ of phosphate buffer was added. Final $A \beta$ : test compound ratio was $1: 1(25 \mu \mathrm{M}: 25 \mu \mathrm{M})$. Plates were incubated on a Fisher plate incubator set to $37^{\circ} \mathrm{C}$ and the contents were shaken at $730 \mathrm{cpm}$ for $24 \mathrm{~h}$. To prepare the TEM grids, $\sim 20 \mu \mathrm{L}$ droplet was added using a disposable Pasteur pipette over the formvar-coated copper grids (400 mesh). Grids were air-dried for about $3 \mathrm{~h}$ before adding two droplets ( $\sim 40 \mu \mathrm{L}$, using a disposable Pasteur pipette) of ultrapure water and using small pieces of filter paper to wash out precipitated buffer salts. After air-drying for $\sim 15-20 \mathrm{~min}$, the grids were negatively stained by adding a droplet $(\sim 20 \mu \mathrm{L}$, using 
a disposable Pasteur pipette) of $2 \%$ phosphotungstic acid (PTA) and immediately after the grids were dried using small pieces of filter paper. Grids were further air-dried overnight. The scanning was carried out using a Philips CM 10 transmission electron microscope at $60 \mathrm{kV}$ (Department of Biology, University of Waterloo) and micrographs were obtained using a 14-megapixel AMT camera. ${ }^{11,30}$

\subsection{Experimental procedure for molecular docking studies}

The modeling experiments were carried out using Discovery Studio (DS), Structure-Based-Design version 4.0, software program from BIOVIA Inc, San Diego, USA. Quinazoline and pyrido[3,2- $d]$ pyrimidine derivatives $8 \mathbf{8 e}, \mathbf{8 h}, \mathbf{9 a}, \mathbf{1 0 b}$ and $\mathbf{1 2 b}$ were built using the small molecules module in DS. For ChE docking studies, the X-ray coordinates of human AChE (pdb id:1B41) and BuChE (pdb id:1P0I) were obtained from protein data bank. The enzymes were prepared for docking using the macromolecules module in DS. The ligand binding site was defined by a 12 $\AA$ sphere for both AChE and BuChE. ${ }^{29,31}$ Docking simulation was carried out using the LibDock algorithm. During the docking simulation, CHARMm force field was used. The docked poses were evaluated using CDOCKER energy, CDOCKER interaction energy in $\mathrm{kcal} \mathrm{mol}^{-1}$ and by considering the type and number of polar and nonpolar contacts. ${ }^{32}$ The molecular docking of test compounds with the $A \beta$ assembly was carried out by using the NMR solution structure (pdb id:2LMN). The $A \beta$ dimer and $A \beta$ fibril assemblies were built using the macromolecules module in DS. ${ }^{32}$ Ligand binding site was defined by selecting a $15 \AA$ radius sphere for both $A \beta$ dimer and fibril assembly. Molecular docking was performed using the receptor-ligand interactions module in DS. The LibDock algorithm was used to find the most appropriate binding modes of quinazoline/pyrido[3,2- $d]$ pyrimidine derivatives ( $\mathbf{8 h}$ and $\mathbf{1 0 b}$ ) using CHARMm force field. The docked poses obtained were ranked based on the LibDock scores and the binding modes were analyzed by evaluating all the polar and nonpolar contacts between the ligands and $A \beta$ dimer and fibril regions.

\subsection{Experimental procedure for iron [Fe(II)] chelation assay}

Determined using the ferrozine (Sigma-Aldrich, USA) based competitive colorimetic assay. ${ }^{23}$ Test compounds were initially dissolved in anhydrous methanol to $10 \mathrm{mM}$ and diluted down to $105 \mu \mathrm{M}$ using $100 \mathrm{mM}$ tris buffer (pH 7.4). Then $95 \mu \mathrm{L}$ of test compound solutions (final concentration of $50 \mu \mathrm{M}$ in each well) were added to clear 96-well plates, followed by a $10 \mu \mathrm{L}$ aliquot of iron sulphate $\left(\mathrm{FeSO}_{4} \cdot 7 \mathrm{H}_{2} \mathrm{O}\right)$ stock solution (from $800 \mu \mathrm{M}$ stock solution prepared in methanol). After a 5 minute incubation period at room temperature, $95 \mu \mathrm{L}$ ferrozine solution (from 210 $\mu \mathrm{M}$ stock solution prepared in tris buffer) was added. After incubating at room temperature for 30 minutes the absorbance was measured at $562 \mathrm{~nm}$ and subtracted from compound blanks ( $95 \mu \mathrm{L}$ of compound solutions $+105 \mu \mathrm{L}$ of tris buffer) and compared to the ferrozine-only positive control $(95 \mu \mathrm{L}$ of tris buffer $+10 \mu \mathrm{L}$ of iron sulphate $+95 \mu \mathrm{L}$ of ferrozine). The results obtained were compared with known iron chelators; clioquinol $(50 \mu \mathrm{M})$ and desferoxamine $(50 \mu \mathrm{M})$. The results were reported as average \% iron-chelation \pm SD in triplicate measurements based on two independent experiments.

\section{Acknowledgements}

The authors would like to thank the Faculty of Science, Office of Research, the School of Pharmacy at the University of Waterloo, Ontario Mental Health Foundation (graduate scholarship for TM), NSERC-USRA (for MM), NSERC-Discovery (RGPIN: 038302014), Canada Foundation for Innovation (CFI-JELF), Ontario Research Fund (ORF) and Early Researcher Award, Ministry of Research and Innovation, Government of Ontario, Canada (PR) for financial support of this research project.

\section{References}

1 A. Cavalli, M. L. Bolognesi, A. Minarini, M. Rosini, V. Tumiatti, M. Recanatini and M. Carlo, J. Med. Chem., 2008, 51, 347-372.

2 J. J. Lu, W. Pan, Y. J. Hu and Y. T. Wang, PLoS One, 2012, 7, e40262.

3 R. E. Hughes, K. Nikolic and R. R. Ramsay, Front. Neurosci., 2016, 10, 177.

4 J. Birks, Cochrane Database Syst. Rev., 2006, CD005593.

5 D. Lo and G. T. Grossberg, Expert Rev. Neurother., 2011, 11, 1359-1370.

6 P. T. Francos, A. M. Pamer, M. Snape and G. K. Wilcock, J. Neurol., Neurosurg. Psychiatry, 1999, 66, 137-147.

7 M. Citron, Nat. Rev. Drug Discovery, 2010, 9, 387-398.

8 M. Rosini, E. Simoni, A. Mielli, A. Minarini and C. J. Melchiorre, J. Med. Chem., 2014, 57, 2821-2831.

9 A. I. Bush, J. Alzheimer's Dis., 2013, 33, S277-S281.

10 T. Mohamed and P. P. N. Rao, Curr. Med. Chem., 2011, 18, 4299-4320.

11 T. Mohamed, A. Shakeri, G. Tin and P. P. N. Rao, ACS Med. Chem. Lett., 2016, 7, 502-507.

12 T. Mohamed and P. P. N. Rao, Eur. J. Med. Chem., 2017, 126, 823-843.

13 S. Darvesh, D. A. Hopkins and C. Geula, Nat. Rev. Neurosci., 2003, 4, 131-138.

14 H. Levine, Protein Sci., 1993, 2, 404-410.

15 G. L. Ellman, K. D. Courtney, V. Andres Jr and R. M. FeatherStone, Biochem. Pharmacol., 1961, 7, 88-95.

16 A. T. Petkova, W. M. Yau and R. Tycko, Biochemistry, 2006, 45, 498-512.

17 G. Kryger, M. Harel, K. Giles, L. Toker, B. Velan, A. Lazar, C. Kronman, D. Barak, N. Ariel, A. Shafferman, I. Silman and J. L. Sussman, Acta Crystallogr., Sect. D: Biol. Crystallogr., 2000, 56, 1385-1394.

18 Y. Nicolet, O. Lockridge, P. Masson, J. C. Fontecilla-Camps and F. Nachon, J. Biol. Chem., 2003, 278, 41141-41147.

19 J. S. Choi, J. J. Braymer, R. P. Nanga, A. Ramamoorthy and M. H. Lim, Proc. Natl. Acad. Sci. U. S. A., 2010, 107, 2199021995.

20 M. G. Savelieff, A. S. DeToma, J. S. Derrick and M. H. Lim, Acc. Chem. Res., 2014, 47, 2475-2482. 
21 M. P. Horowitz and J. T. Greenamyre, J. Alzheimer's Dis., 2010, 20, S551-S568.

22 L. X. Yang, K. X. Huang, H. B. Li, J. X. Gong, F. Wang, Y. B. Feng, Q. Tao, Y. H. Wu, X. K. Li, X. M. Wu, S. Zeng, S. Spencer, Y. Zhao and J. Qu, J. Med. Chem., 2009, 52, 7732-7752.

23 M. Karamac, Int. J. Mol. Sci., 2009, 10, 5485-5497.

24 R. A. Smits, I. J. de Esch, O. P. Zuiderveld, J. Broeker, K. Sansuk, E. Guaita, M. Adami, E. Haaksma and R. Leurs, J. Med. Chem., 2008, 51, 7855-7865.

$25 \mathrm{Z}$. Li, D. Wu and W. Zhong, Heterocycles, 2012, 85, 14171426.

26 A. Tikad, S. Routier, M. Akssira, J. M. Leger, C. Jarry and G. Guillaumet, Synlett, 2006, 12, 1938-1942.
27 T. Mohamed, J. C. Yeung, M. S. Vasefi, M. A. Beazely and P. P. N. Rao, Bioorg. Med. Chem. Lett., 2012, 22, 4707-4712.

28 T. Mohamed, A. Assoud and P. P. N. Rao, Acta Crystallogr., Sect. E: Struct. Rep. Online, 2014, 70, 0554.

29 T. Mohamed, X. Zhao, L. K. Habib, J. Yang and P. P. N. Rao, Bioorg. Med. Chem., 2011, 19, 2269-2281.

30 V. L. Anderson, T. F. Ramlal, C. C. Rospigliosi, W. W. Webb and D. Eliezer, Proc. Natl. Acad. Sci. U. S. A., 2010, 107, 1885018855.

31 G. Tin, T. Mohamed, N. Gondora, M. B. Beazely and P. P. N. Rao, MedChemComm, 2015, 6, 1907-2044.

32 P. P. N. Rao, T. Mohamed, K. Teckwani and G. Tin, Chem. Biol. Drug Des., 2015, 86, 813-820. 